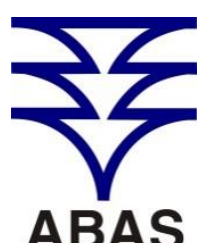

associaḉo brasileirade www.abas.org

\title{
RADAR DE PENETRAÇÃO NO SOLO APLICADO À ANÁLISE AMBIENTAL DE POSTO DE COMBUSTÍVEIS PÓS-REMEDIAÇÃO
}

\author{
GROUND PENETRATING RADAR APPLIED TO ENVIRONMENTAL \\ ANALYSIS POST REMEDIATION GAS STATIONS
}

\author{
Danusa Mayara de Souza ${ }^{1}$; José Gouvêa Luiz ${ }^{2}$
}

Artigo recebido em: 03/01/2017 e Aceito para publicação em: 02/05/2017.

DOI: http://dx.doi.org/10.14295/ras.v31i3.28797

\begin{abstract}
Resumo: As águas subterrâneas são menos vulneráveis à contaminação do que as águas superficiais, todavia, uma vez gerada a contaminação, pode levar diversos anos para que o ambiente seja recuperado e até mesmo se tornar inviável economicamente, sua recuperação. Devido à ocupação urbana, as águas subterrâneas estão expostas a diversos tipos de contaminantes e entre eles estão os combustíveis, seja por vazamentos em tanques e linhas, seja por derramamento. Os hidrocarbonetos têm elevada resistividade elétrica, e por esse motivo, ao serem derramados no solo elevam a resistividade do ambiente em subsuperfície. Comumente, com o passar do tempo, a ação de bactérias nos compostos orgânicos dos combustíveis produz a sua biodegradação com a formação de ácidos que dissolvem íons do material do subsolo, fazendo com que a resistividade elétrica diminua bastante, transformando o ambiente em um bom condutor de eletricidade. Neste trabalho se pretendeu detectar a assinatura (resistiva ou condutiva) de anomalias associadas a derrames no Posto Braz de Aguiar em Belém/PA, que se encontra desativado. O levantamento geofísico foi realizado com o Radar de Penetração no Solo (GPR), usando uma antena de frequência central de $400 \mathrm{MHz}$, sendo os dados processados com o software REFLEXW. Uma assinatura de baixa resistividade foi detectada mesmo após a remediação do posto em estudo.
\end{abstract}

Palavras-chave: Água subterrânea. Contaminação. Posto de Combustíveis. Belém. GPR.

\begin{abstract}
Underground aquifers are much less vulnerable to contamination than surface waters; however, once contamination has occurred, its recovery, depending on the type of contaminant, can take many years and even become economically unfeasible. Due to urban occupation, groundwater is exposed to several types of contaminants and among them are the hydrocarbons. The fuels derived from petroleum have a high electric resistivity and when spilled on the ground increase the resistivity of the environment. After some time, commonly, the action of bacteria over the organic compounds of fuels produce their biodegradation with the formation of acid that dissolve ions of the material of the ground, lowering the electric resistivity and transforming the environment into a good conductor of electricity. In this work it was intended to detect the signature in terms of resistivity of anomalies associated to contamination by fuels derived from hydrocarbons at the Braz de Aguiar Gas Station, a deactivated station, located in Belém/PA. The geophysical measurements were carried through with the Ground Penetrating Radar (GPR) using a $400 \mathrm{MHz}$ antenna and the data were processed with the REFLEXW software. A low resistivity signature was detected even after the remediation performed in the study gas station.
\end{abstract}

Keywords: Groundwater. Contamination. Gas Station. Belém. GPR.

\section{INTRODUÇÃO}

Crescentes casos de contaminação de água subterrânea por vazamentos de hidrocarbonetos estão, muitas vezes, associados ao fim da vida útil dos tanques subterrâneos armazenadores de combustíveis, que é de aproximadamente 20 anos, podendo ser reduzida para 10 anos se o tanque se encontrar desprotegido (sem jaqueteamento proteção catódica). As águas subterrâneas são menos vulneráveis à contaminação do que as águas superficiais; todavia, uma vez contaminadas, pode levar diversos anos para

\footnotetext{
1-2 Universidade Federal do Pará (UFPA), Belém, PA. E-mails: (danusa@ufpa.br, gouvea@ufpa.br)
} 
que o ambiente seja recuperado ou até mesmo se tornar inviável economicamente (FEITOSA e MANOEL FILHO, 1997).

A Geofísica pode possibilitar/auxiliar na prevenção (delimitação de áreas próprias à instalação), remediação (acompanhamento 4D) e monitoramento de impactos ambientais (como lixões, cemitérios, postos de combustíveis, curtumes, rochas e materiais radioativos), que normalmente contaminam o solo, subsolo e recursos hídricos.

Aplicação de técnicas Geofísicas como o Radar de Penetração no Solo (GPR) em estudos ambientais pode ser considerado vantajoso, pois permite a execução de perfis contínuos e com alta resolução, apresenta facilidade de aquisição de dados, realização de medidas com diversas frequências e devido à versatilidade do equipamento em campo, possibilita a aplicação inclusive em áreas urbanas. Quando comparada com outras técnicas de investigação, este método possui uma boa relação de custo/benefício aliada à rapidez de execução das medidas.

Neste trabalho foi empregado o GPR em áreas sujeitas a contaminações por derivados de hidrocarbonetos (combustíveis automotivos) em um posto de serviço já desativado e parcialmente remediado; localizado na cidade de Belém/PA.

\section{O MÉTODO GPR}

O Radar (RAdio Detection And Ranging) de Penetração no Solo, também é conhecido como radar de prospecção geotécnica (em Portugal), earth sounding radar, georadar, ground probing radar, radar terrestre penetrant, subsurface radar, surface penetrating radar, tendo como principal e mais conhecida nomenclatura ground penetrating radar - GPR ou, simplesmente, radar.

O GPR conta com a vantagem de ser uma técnica não destrutiva e não invasiva, além de fornecer seções amigáveis à geologia e possuir um vasto leque de aplicações que podem variar de acordo com a frequência da antena utilizada, limitando-se, claro, à Geofísica Rasa, uma vez que se trata de um método de alta frequência $\mathrm{e}$ consequentemente baixa profundidade de investigação (com exceção quando aplicado no gelo).

As principais aplicações do GPR são mapeamento de feições geológicas, geotecnia (edificações civis, asfalto, tubulações, pistas de aterrissagem, pisos e calçadas), meio ambiente (lixões, aterros sanitários, curtumes, postos de serviços, refinarias, fábricas $\mathrm{e}$ cemitérios), geofísica legal (criminalística, forense, inspeções e identificações de artefatos explosivos enterrados), arqueologia (utensílios e edificações de povos antigos), estudos de permafrost (gelo) e paleontologia.

A literatura sobre o método é bem ampla e a utilização do método GPR aplicado a derrames de derivados de hidrocarbonetos é bem diversificada, podendo ser observada nos estudos de Bermejo et al. (1997) sobre combustíveis de aviação; Atekwana et al. (2000) sobre óleo bruto em uma refinaria; Orlando (2002) sobre gasolina e diesel em um oleoduto; Pettersson e Nobes (2003) sobre combustíveis armazenados sobre o gelo; Castro et al. (2003) sobre monitoramento da contaminação por hidrocarbonetos durante a remediação; Pedrosa (2004) sobre vazamento de gasolina em postos de serviço; Borges et al. (2006) sobre óleos lubrificantes descartados indevidamente em cavas.

O Radar de Penetração no Solo é um método geofísico baseado na propagação de ondas eletromagnéticas (EM) de alta frequência. A partir de uma antena transmissora são emitidas ondas de energia EM na faixa de $10 \mathrm{MHz}$ a $1 \mathrm{GHz}$. Cada antena (das várias disponíveis) possui uma frequência central de operação e esta deve ser escolhida de acordo com o interesse da investigação. Quanto maior a frequência, maior a resolução e menor profundidade de investigação. Em estudos ambientais, as frequências mais utilizadas são as de $80 \mathrm{MHz}$, $400 \mathrm{MHz}$ e $800 \mathrm{MHz}$, pois são capazes de imagear a subsuperfície a uma profundidade e resolução satisfatórias.

A interação das ondas EM com o meio subterrâneo será influenciada pelas propriedades físicas dos materiais. Portanto, 
são relevantes nesse processo, a constituição mineralógica, bem como a quantidade de argila, minerais metálicos e água.

A seção resultante, o radargrama, é formada por cada traço (scan) representativo dos tempos de chegada dos pulsos refletidos, bem como o pulso transmitido pelo ar mais a onda direta que se propaga pelo solo (Figura 1). As reflexões primárias se apresentam em tempos posteriores (ou maiores) no scan. Conforme é deslocada a antena sobre o terreno, são registrados diferentes scans em diferentes pontos. $\mathrm{O}$ conjunto de scans posicionados lado a lado (Figura 1), na sequência de suas aquisições, forma uma imagem, que posteriormente é tratada com vistas aos objetivos do levantamento.

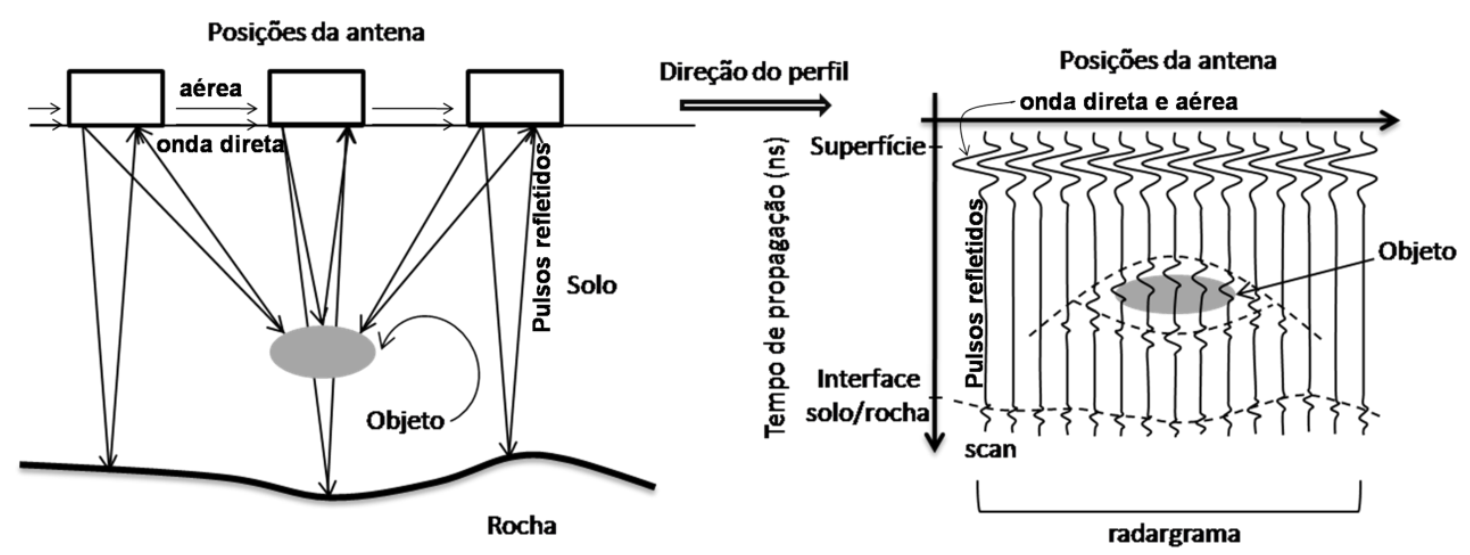

Figura 1 - Exemplificação de um levantamento GPR e ilustração de um radargrama (adaptado de DAVIS e ANNAN, 1989)

Figure 1 - Exemplification of a GPR survey and illustration of a radargram (adapted from DAVIS and ANNAN, 1989)

3 CARACTERÍSTICAS DOS HIDROCARBONETOS E INTERAÇÃO COM AS ÁGUAS SUBTERRÂNEẢS

Hidrocarbonetos são compostos químicos orgânicos formados, essencialmente, por hidrogênio $(\mathrm{H})$ e carbono $(\mathrm{C})$, podendo ter em suas cadeias átomos de oxigênio $(\mathrm{O})$, nitrogênio $(\mathrm{N})$ e enxofre $(\mathrm{S})$. Os principais derivados de hidrocarbonetos utilizados como combustíveis são: a gasolina $\left(\mathrm{C}_{8} \mathrm{H}_{18}\right)$, o óleo diesel $\left(\mathrm{C}_{12} \mathrm{H}_{26}\right)$, o querosene $\left(\mathrm{C}_{16} \mathrm{H}_{34}\right)$ e o querosene de aviação $\left(\mathrm{C}_{9} \mathrm{H}_{20}\right)$. O álcool, etanol $\left(\mathrm{C}_{2} \mathrm{H}_{5} \mathrm{OH}\right)$, composto orgânico, mas um derivado não fóssil possui em sua fórmula molecular átomos de hidrogênio $(\mathrm{H})$ e carbono (C) ligados a um grupamento hidroxila $(\mathrm{OH})$ e normalmente é misturado a gasolina no caso do Brasil.

A contaminação de águas subterrâneas por combustíveis derivados da destilação do petróleo tem sido objeto de crescente pesquisa no Brasil. Os compostos hidrocarbonetos monoaromáticos benzeno, tolueno, etilben- zeno e xilenos (denominados BTEX), presentes nesses combustíveis, são extremamente tóxicos à saúde humana e podem inviabilizar a exploração de aquíferos por eles contaminados.

Os compostos hidrocarbonetos são classificados como "compostos de fase líquida não aquosa" (nonaqueous phase liquids, NAPLs), devido as suas propriedades físicas e químicas e são imiscíveis em água. Eles são divididos em duas classes: "compostos de fase líquida leve não aquosa" (ligth nonaqueous phase liquid, LNAPL), representados, principalmente, pelos BTEX e "compostos de fase líquida densa não aquosa" (dense nonaqueous phase liquid, DNAPL) caso dos óleos lubrificantes (BREWSTER e ANNAN, 1994).

Os maiores problemas de contaminação são atribuídos aos hidrocarbonetos monoaromáticos (LNAPL), constituintes mais solúveis e mais móveis da fração da gasolina. Os valores máximos permitidos para os diferentes hidrocarbonetos monoa- 
romáticos, de acordo com o estabelecido pela Portaria n ${ }^{\circ}$ 518/GM de 25/03/2004, são: $5 \mu \mathrm{g} / 1$ para o benzeno, $170 \mu \mathrm{g} / 1$ para o tolueno, 200 $\mu \mathrm{g} / 1$ para o etilbenzeno e $300 \mu \mathrm{g} / 1$ para o xileno.

Como a gasolina produzida no país contém de $22 \%$ a $26 \%$ de álcool, as interações entre o etanol e os compostos BTEX podem causar um comportamento anômalo da pluma de contaminação daquele observado em outros países em que a gasolina não contém etanol. A presença de etanol pode facilitar a dissolução dos BTEX em água, aumentos da mobilidade dos BTEX dissolvidos na água subterrânea além de reduzirem a biodegradação natural dos BTEX. Consequentemente, as plumas no Brasil podem ser maiores, deslocarem-se mais rapidamente e por áreas mais extensas, além de persistirem mais tempo do que nos países em que o álcool não é misturado à gasolina. (CORSEUIL e ALVAREZ, 1996).

Os combustíveis fósseis têm uma elevada resistividade elétrica e por esse motivo, ao serem derramados no solo elevam a resistividade do ambiente. Comumente, com o passar do tempo, a ação de bactérias produz a biodegradação dos compostos orgânicos presentes nas plumas contaminantes. Esse processo forma ácidos que dissolvem íons do material do subsolo, fazendo com que a resistividade elétrica diminua bastante, o que transforma o ambiente em um bom condutor de eletricidade.

Em resumo, o derramamento de combustíveis derivados de hidrocarbonetos produz plumas de contaminação que têm sido associadas, em levantamentos geofísicos, tanto a valores elevados de resistividade elétrica, como a baixíssimos valores de resistividade (valores condutivos). Exemplo histórico de pluma resistiva é descrito por Benson et al. (1997), que realizaram análises de vazamento de gasolina em um posto de serviço em Utah e identificaram zonas resistivas coincidentes com as áreas de derrames recentes. Um exemplo histórico de pluma condutiva é descrito por Sauck et al. (1998), que verificaram os efeitos da utilização de combustíveis derramados no solo para treinamento de incêndios em uma base da força aérea em Michigan e mapearam zonas condutivas coincidentes com derrames mais antigos. Em estudos atuais, a assinatura resistiva dos derrames pode ser observada em Marques (2007) que as associou à alta cargabilidade em um posto de combustíveis e em Haynie e Khan (2016) que localizou anomalias em locais de derrame de hidrocarbonetos em uma ilha. A assinatura condutiva de contaminação por hidrocarbonetos pode ser notada em Almeida et al. (2007) e em Silva (2013) que correlacionaram as atenuações nos dados de GPR às plumas condutivas ocasionadas por vazamentos em postos de combustíveis.

\section{SISTEMA DE AQUISIÇÃO E TRATA- MENTO DE DADOS}

Para a realização do levantamento se utilizou o equipamento TerraSIRch SIR (Subsurface Interface Radar) System-3000 da GSSI (Geophysical Survey Systems, Inc.) e uma antena blindada de $400 \mathrm{MHz}$ (Modelo 5103).

A profundidade de penetração e a resolução do levantamento GPR dependem de vários fatores, todavia, com uma antena de $400 \mathrm{MHz}$ se alcança uma profundidade de aproximadamente $4 \mathrm{~m}$, assumindo-se a constante dielétrica igual a 5 (GSSI, 2003). O alcance (range) depende dos ajustes feitos no equipamento antes do levantamento, mas normalmente é de $50 \mathrm{~ns}, 512$ amostras por scan, 64 scans por segundo, uma taxa de transmissão de $100 \mathrm{KHz}$ e uma resolução de 16 bits (dado no formato *.dzt).

As medidas nas áreas do posto foram realizadas ao longo de perfis no modo tempo (modo contínuo), metodologia de aquisição em que a antena é arrastada sobre solo de forma contínua, sendo o sinal oriundo do meio registrado sequencialmente em intervalos de tempo fixos, na medida em que passa sobre os alvos investigados. $\mathrm{O}$ controle da distância e posicionamento das medidas foi feito a partir da inserção de marcas no registro a intervalos de $5 \mathrm{~m}$.

Os dados obtidos com o GPR foram 
processados com o software Sandmeier REFLEXW versão 7.0, com a finalidade de melhorar a visualização dos registros.
No presente estudo se realizou a sequência de processamento ilustrada no fluxograma apresentado na Figura 2.

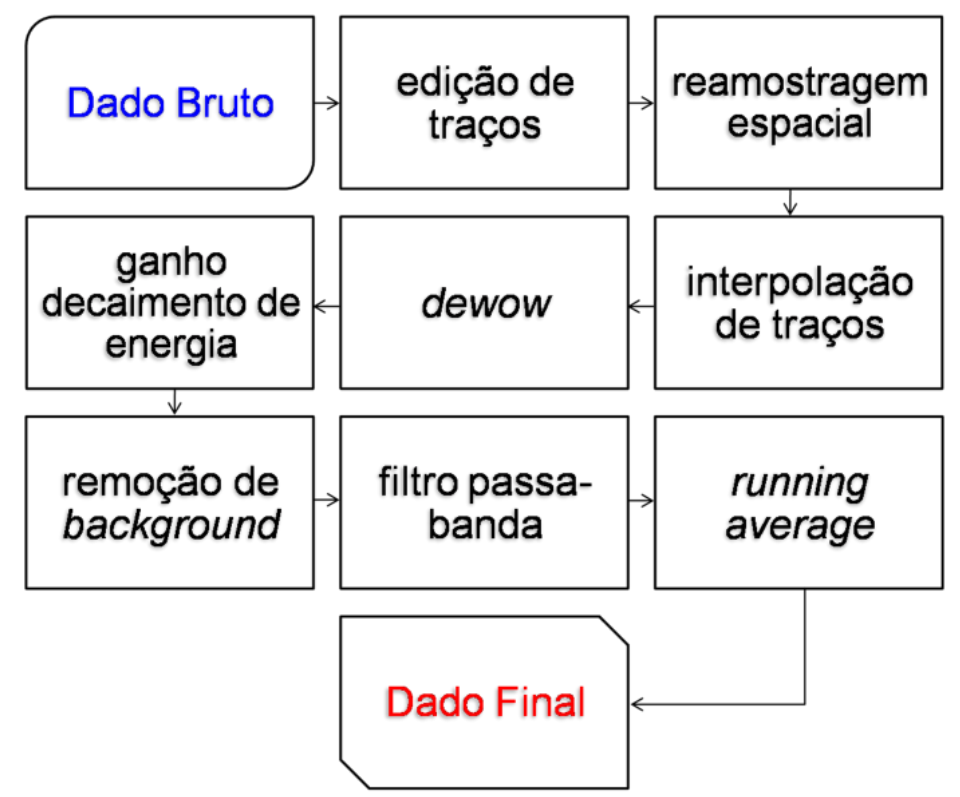

Figura 2 - Sequência de processamento Figure 2 - Processing sequence

A profundidade de investigação foi estimada a partir da velocidade de $0,166 \mathrm{~m} / \mathrm{ns}$ que foi obtida através da superposição de hipérboles (abertura igual a 20 - menor abertura adquirida).

\section{APRESENTAÇÃo DA ÁREA DE ESTUDO E RESULTADOS}

O levantamento foi realizado em um posto de serviços desativado e denominado, neste estudo, de Posto Braz de Aguiar, pois está localizado na Av. Braz de Aguiar entre a Trav. Dr. Moraes e a Trav. Benjamin Constant no bairro de Nazaré em Belém/PA. Eram comercializados neste posto, gasolina comum (1 bomba), gasolina aditivada ( 2 bombas) e álcool etílico hidratado comum ( 2 bombas). $\mathrm{O}$ posto possuía 2 tanques de $15 \mathrm{~m}^{3}$ (gasolina comum e álcool) e 1 tanque de $30 \mathrm{~m}^{3}$ (gasolina aditivada).

$\mathrm{O}$ posto funcionava com bandeira Texaco (CHEVRON) e funcionou por mais de 20 anos. Foi desativado em 2004 e passou por um processo de remediação iniciado no mesmo ano. Segundo Coutinho e Gomes (2007) foi encontrada a presença de xilenos e
PAH (hidrocarbonetos aromáticos policíclicos) dissolvidos na água subterrânea através de poços de monitoramento instalados no posto. Em seguida, o processo de remediação do posto foi iniciado e consistiu de um sistema Multifase com poços de bombeamento para retirada da fase líquida, fase dissolvida e extração dos vapores. $\mathrm{O}$ sistema operou durante 10 meses e foi desligado assim que o valor do LIE (Limite Inferior de Explosividade) atingiu valor nulo. Ao final, o sistema recuperou 221 litros dos contaminantes em fase livre e aproximadamente $492 \mathrm{Kg}$ da massa de VOC (compostos orgânicos voláteis).

A geologia da região em que se encontra o posto é composta por sedimentos do Quaternário Pleistoceno da Formação PósBarreiras, com areias de granulometria fina a média, moderadamente selecionadas e seixos de quartzo leitoso associados, bem como por sedimentos do Terciário Mioceno da Formação Barreiras, com horizontes de arenitos ferruginosos (lateritas também conhecidas como Grês do Pará) e argilas logo abaixo (BARBOSA, 2000 e NASCIMENTO, 2003). O nível freático da área em estudo está 
entre 1 a $4 \mathrm{~m}$ de profundidade e varia, chuvosas (CATETE, 2010 e MENDES, principalmente, ao final das épocas mais 2000).

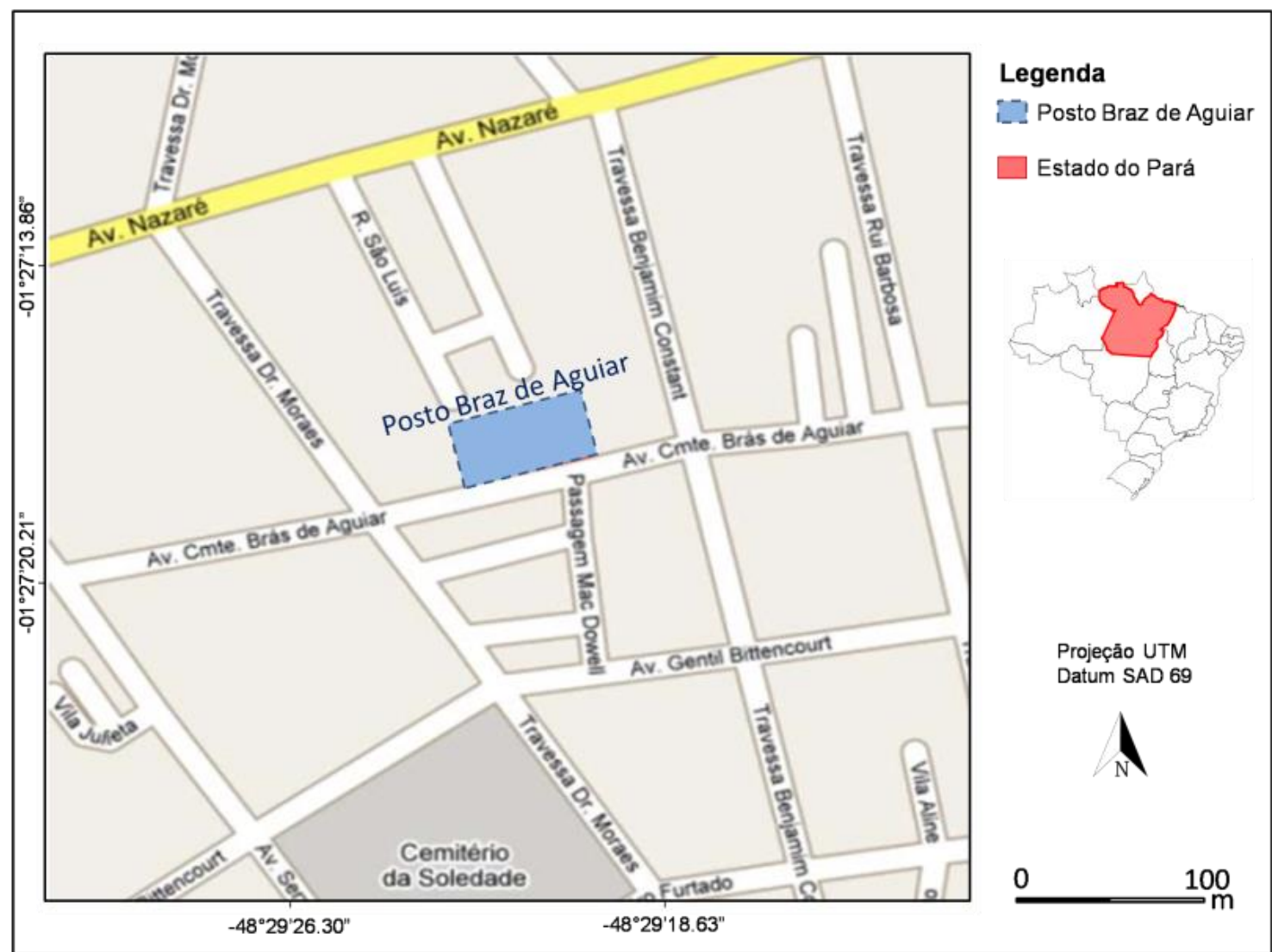

Figura 3 - Localização do Posto Braz de Aguiar (em azul) - Belém/PA (adaptada de GOOGLE MAPS e georreferenciada pelo QuantumGIS)

Figure 3 - Location of Braz de Aguiar Gas Station (in bluel) - Belem/PA (adapted from GOOGLE MAPS and georeferenced by QuantumGIS)

O levantamento consistiu de 6 perfis de caminhamento no modo temporal usando a técnica common offset com marcações a cada $1 \mathrm{~m}$ (Perfil 5 e 6), $2 \mathrm{~m}$ (Perfil 1, 3 e 4) e $5 \mathrm{~m}$
(Perfil 2) na área interna do posto. O comprimento dos perfis é mostrado na Tabela 1 e a posição dos perfis é ilustrada na Figura 4.

Tabela 1 - Comprimento dos perfis adquiridos

Table 1 - Profiles length

Identificação dos perfis
Perfil 1
Perfil 2
Perfil 3
Perfil 4
Perfil 5
Perfil 6

Extensão
$18 \mathrm{~m}$
$38 \mathrm{~m}$
$10 \mathrm{~m}$
$16 \mathrm{~m}$
$3 \mathrm{~m}$
$6 \mathrm{~m}$




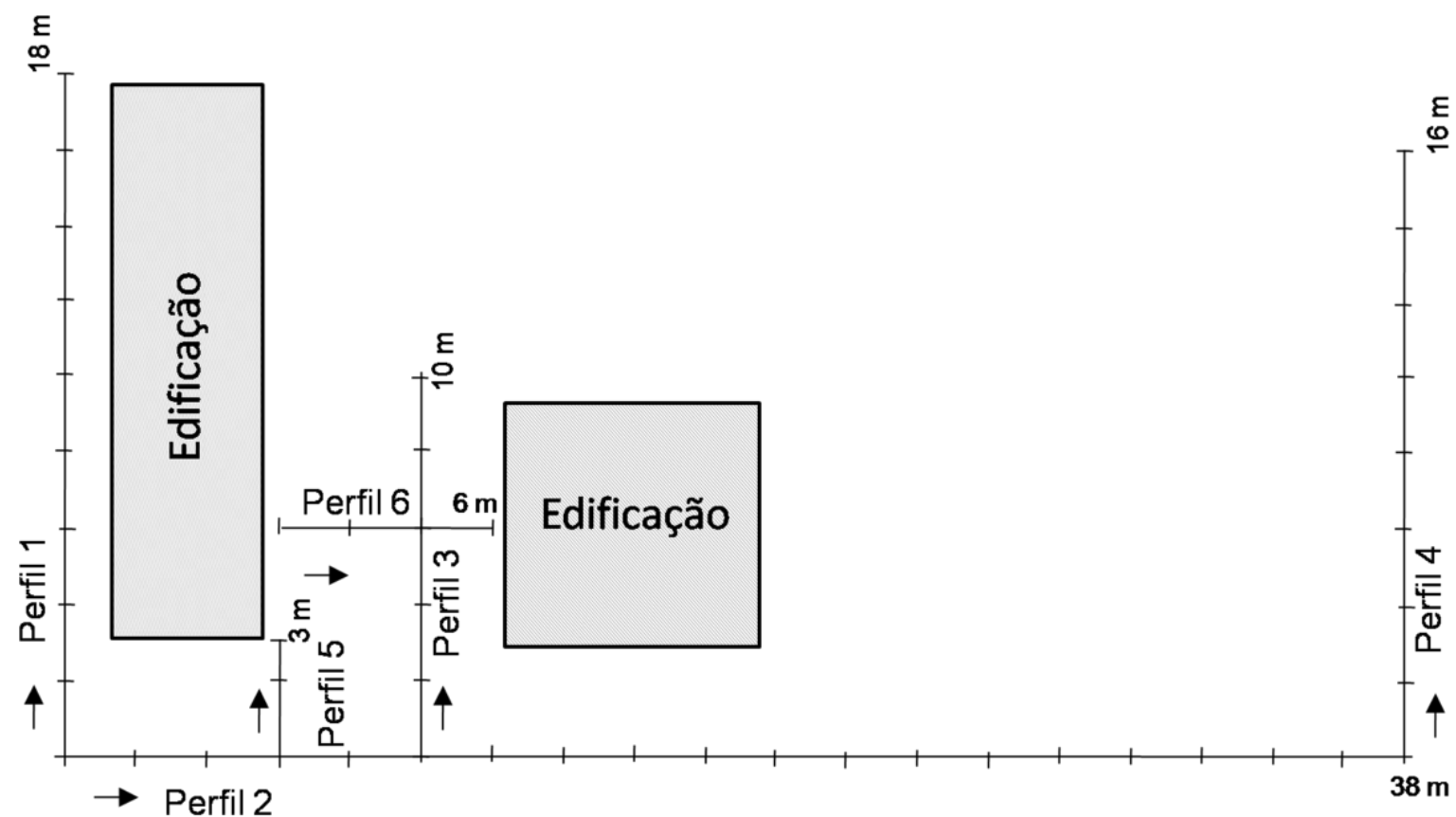

Figura 4 - Disposição dos perfis no Posto Braz de Aguiar

Figure 4 - Profile layout at Gas Station Braz de Aguiar

Os perfis 1,2 e 3 foram realizados muito próximos à localização dos tanques subterrâneos e tubulações de combustível do posto. O perfil 4 foi executado nos fundos do posto, afastado dos tanques e tubulações. Os perfis 5 e 6 foram adquiridos entre as edificações e logo acima de uma tubulação com localização previamente conhecida.

Analisando o radargrama dos dados adquiridos, observa-se tubulações no início do Perfil 1 (Figura 5), que evidenciam diversas zonas de atenuação do sinal que podem ser devidas à contaminação. Essas zonas ocorrem entre as posições horizontais de $6 \mathrm{~m}$ a $16 \mathrm{~m}$, iniciando na profundidade de $1 \mathrm{~m}$ (destacadas na imagem) e em todo o perfil, a partir da profundidade de $2 \mathrm{~m}$.

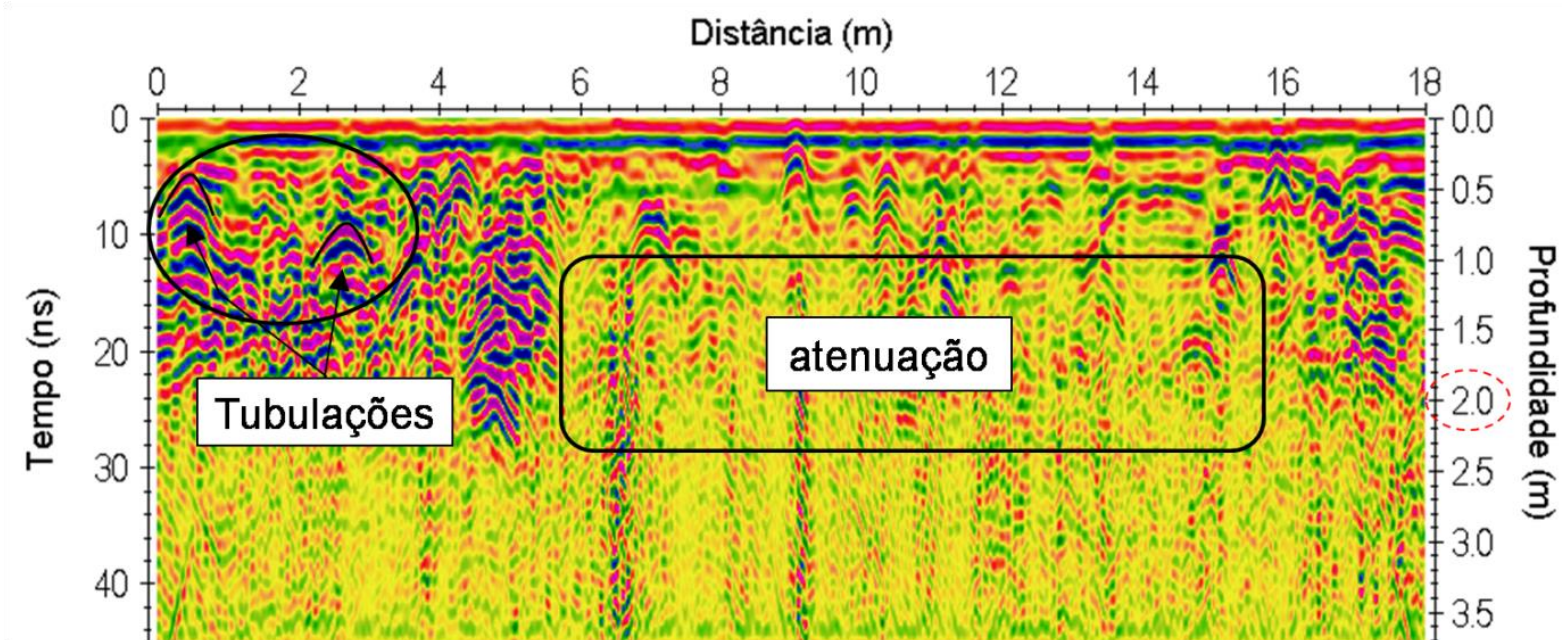

Figura 5 - Perfil 1 evidenciando zonas de atenuação do sinal quebrando a continuidade lateral e vertical da seção

Figure 5 - Profile 1 evidenced signal attenuation zones breaking the lateral and vertical continuity of the section 
O perfil 2 (Figura 6) apresenta um conjunto de feições subverticais que podem ter sido ocasionadas pela mesma tubulação do início do perfil 1 (Figura 5), uma vez que os perfis têm seu início no mesmo ponto com direções diferentes. Uma zona com refletores horizontais paralelos é vista entre $13 \mathrm{~m}$ a $19 \mathrm{~m}$ e, provavelmente, foi provocada por um tanque de combustível disposto paralelamente ao perfil. No perfil, observam-se zonas de atenuação do sinal aproximadamente, a partir de $1 \mathrm{~m}$ de profundidade entre $8 \mathrm{~m}$ a $12 \mathrm{~m}$ e entre $20 \mathrm{~m}$ a $29 \mathrm{~m}$. Essas zonas apresentam comportamento de pluma de derivados de hidrocarbonetos degradados ou em degradação, por atenuarem o sinal emitido pelo GPR e quebrarem a continuidade lateral esperada para o local do perfil, que possui um substrato mais resistivo.

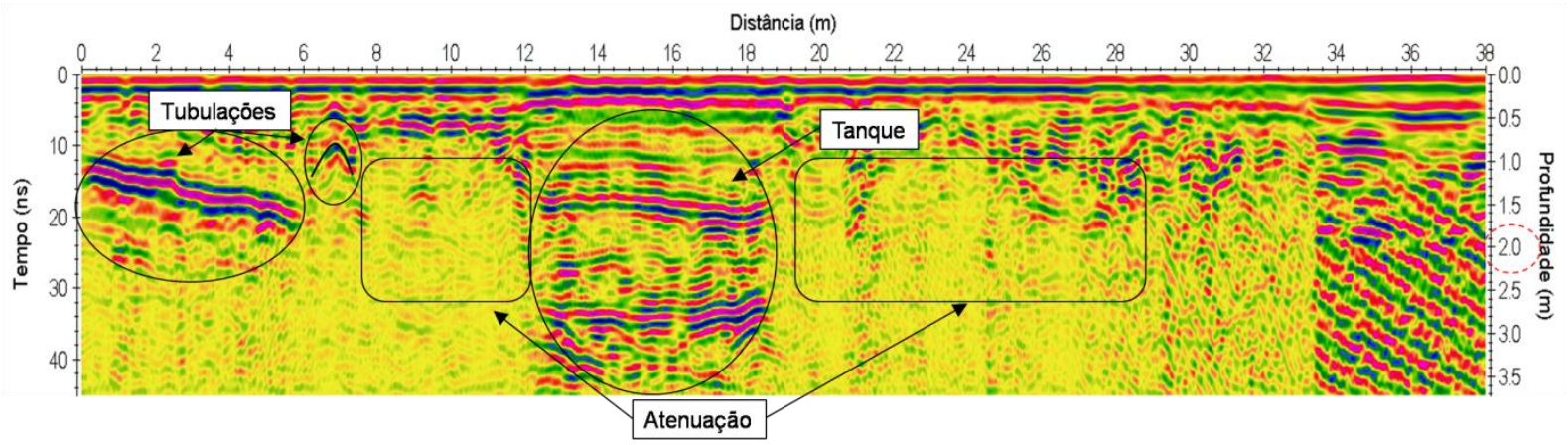

Figura 6 - Perfil 2 mostrando a posição dos tanques e tubulações, além de zonas de atenuação do sinal Figure 6 - Profile 2 showing tubes and tanks position, beyond signal attenuation zones

O perfil 3 (Figura 7) evidencia fortes reflexões nas posições horizontais até $2 \mathrm{~m}$ que podem ter sido provocadas por tubulações. Nesse perfil, ocorrem fortes atenuações no sinal entre as distancias de $4 \mathrm{~m}$ a $10 \mathrm{~m}$ a uma profundidade superior a $2 \mathrm{~m}$. Essas atenuações podem ser ocasionadas em razão da contaminação, bem como à composição geológica do terreno, já que ocorrem em profundidades superiores às profundidades com atenuações encontradas nos outros perfis. $\mathrm{Na}$ profundidade de $1,5 \mathrm{~m}$ é possível notar uma reflexão semelhante a esperada para o nível freático.

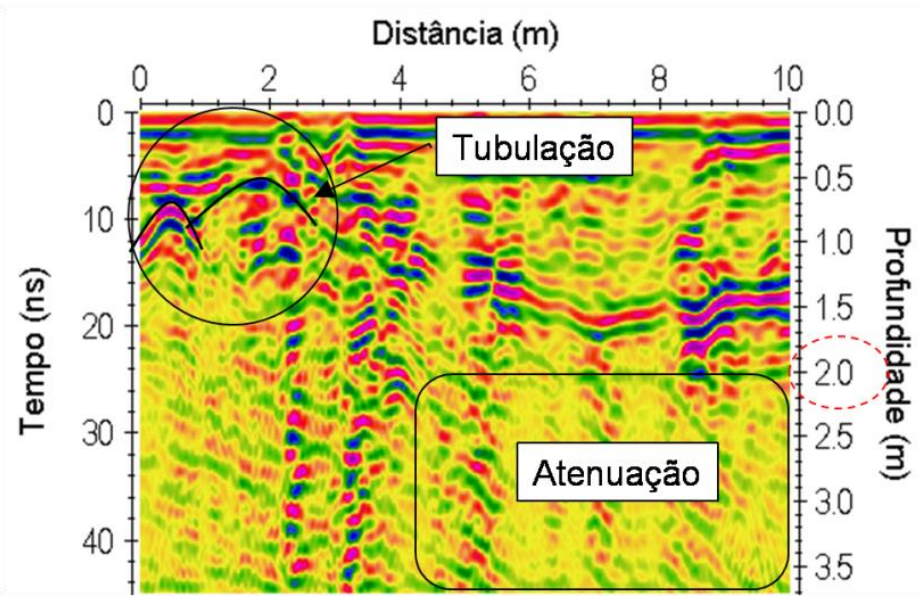

Figura 7 - Perfil 3 ilustrando zonas atenuadas abaixo de $2 \mathrm{~m}$ de profundidade

Figure 7 - Profile 3 illustrating attenuation zones below $2 \mathrm{~m}$ depth

O perfil 4 (Figura 8) foi realizado nos fundos do posto, longe da área em que se encontravam os tanques. Neste perfil, as zonas de atenuação do sinal ocorrem em profundidades maiores que $2 \mathrm{~m}$ e devem ter sido ocasionadas pela composição mineralógica do local. 


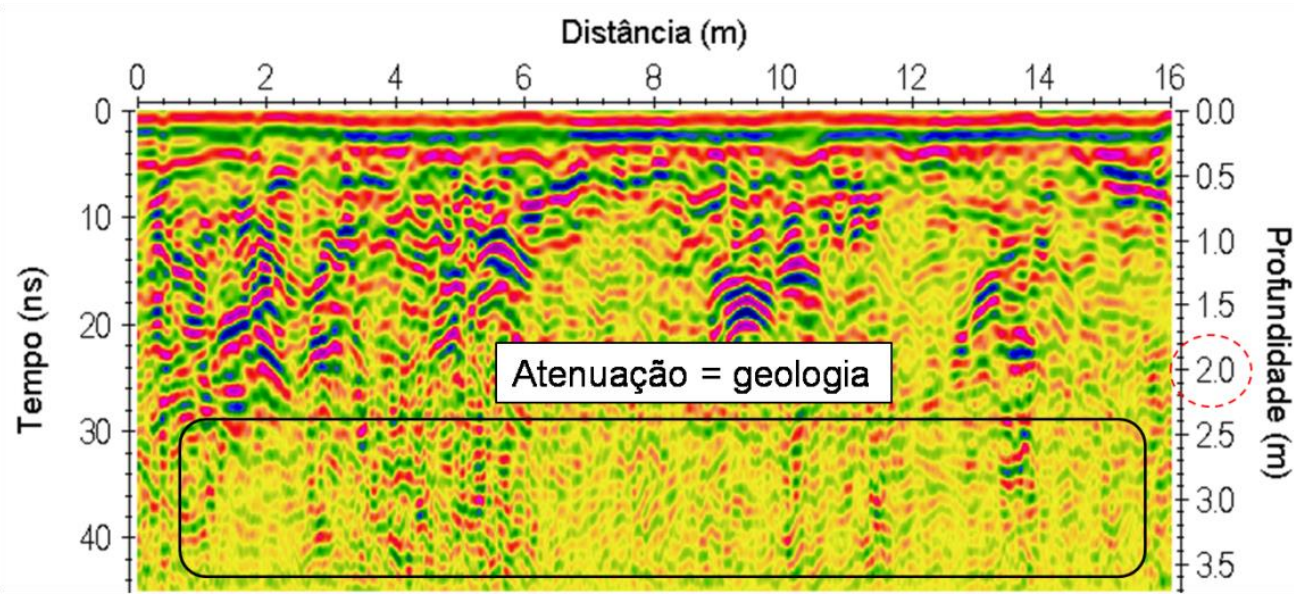

Figura 8 - Perfil 4 com áreas de atenuação devido a geologia

Figure 8 - Profile 4 with attenuation areas due to geology

O Perfil 5 e o Perfil 6 (Figura 9) foram influência (resposta) no perfil. A feição é realizados bem em cima de uma conhecida imageada com clareza e boa resolução. tubulação a fim de verificar seu nível de
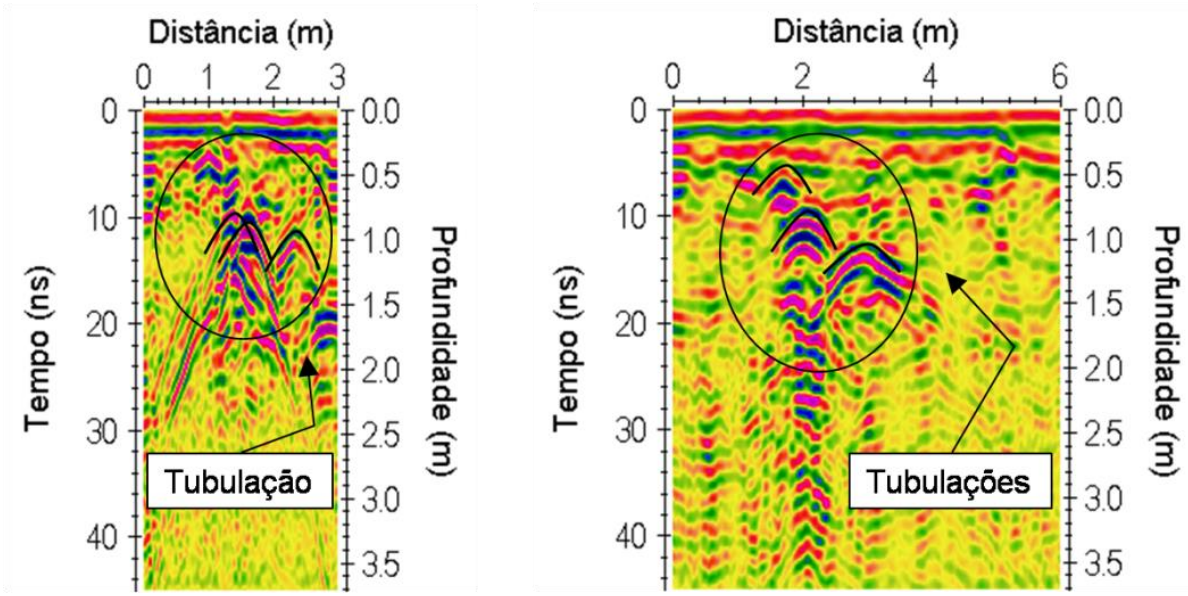

Figura 9 - Perfil 5 (esquerda) e Perfil 6 (direita), ambos evidenciando tubulações Figure 9 - Profile 5 (left) and Profile 6 (right), both evidencing tubings

\section{CONCLUSÕES E RECOMENDAÇÕES}

Regiões de derrames de gasolina tendem, conforme a literatura estudada, a apresentar altas resistividades em períodos iniciais em relação ao substrato. Entretanto, em alguns casos, as plumas de contaminação ao interagirem com os microorganismos, tendem a serem degradadas e os hidrocarbonetos que foram decompostos podem vir a se tornar ácido carbônico, transformando o ambiente em um bom condutor de eletricidade. $\mathrm{O}$ aumento da condutividade elétrica dessas zonas em relação ao ambiente provoca atenuação do sinal de GPR.
Os dados obtidos no posto de serviço Braz de Aguiar evidenciaram diversas zonas de atenuação do sinal de GPR localizadas às proximidades de tanques e tubulações subterrâneas mesmo já tendo sido feita a remedição. O esperado para a área de estudo seria um ambiente sem focos de atenuação do sinal. Esse fato e a correlação dos perfis adquiridos com resultados de levantamentos descritos anteriormente sugerem que as zonas condutivas são devidas às contaminações por resíduos oriundos de derivados de hidrocarbonetos que ainda se encontram em fase de biodegradação. Todavia como a geofísica toma medidas indiretas da subsuperfície, não se pode afirmar que a área 
esteja contaminada e sim que ainda existe forte suspeita da presença dos fluidos contaminantes devido à assinatura característica nos dados adquiridos. Algumas das zonas de atenuação, entretanto, devido a sua maior profundidade de ocorrência, podem ser relacionadas à composição geológica do terreno em subsuperfície.

\section{REFERÊNCIAS}

ALMEIDA, F. M.; SOUZA, D. M.; LUIZ, J. G. Estudo da contaminação por hidrocarbonetos em postos de serviços de Abaetetuba-PA utilizando georadar. $X$ Congresso Internacional do Sociedade Brasileira de Geofísica. 2007. 6 p.

ATEKWANA, E. A., SAUCK, W. A.; WERKEMA Jr., D. D. Investigations of geoelectrical signatures at a hydrocarbon contaminated site. Journal of Applied Geophysics, v. 44, p. 167-180. 2000.

BARBOSA, A. V. C. Aplicação de sondagem elétrica e GPR no mapeamento geotécnico no município de Belém - PA. Dissertação de Mestrado em Geofísica. Universidade Federal do Pará. 2000. 113 p.

BENSON, A.K.; PAYNE, K.L.; STUBBEN, M.A. Mapping Groundwater Contamination using dc Resistivity and VLF Geophysical Methods-a Case Study. Geophysics, v. 62 (1), p. 80-86. 1997.

BERMEJO, J. L.; SAUCK, W. A.; ATEKWANA, E. A. Geophysical Discovery of a New LNAPL Plume at the Former Wurtsmith $\mathrm{AB}$, Oscoda, Michigan. Fall GWMR, v. 133, p. 131-137. 1997

BORGES, W. R.; LAGO, A.; FACHIN, S.; ELIS, V.; SANTOS, E. GPR Utilizado na Detecção da Geometria de Cavas Usadas para Disposição de Resíduos de Óleo Lubrificantes. Revista Brasileira de Geofísica, v. 24 (4), p. 483-494. 2006.

BREWSTER, M. L.; ANNAN, A. P. Groundpenetrating radar monitoring of a controlled DNAPL release: $200 \mathrm{MHz}$ radar. Geophysics, v. 59 (8), p. 1211-1221. 1994.

CATETE, C. P. Investigações ambiental e forense com os métodos geofísicos Radar de Penetração do Solo, Polarização Induzida e
Eletrorresistividade no Cemitério do Tapanã, Belém/Pará. Dissertação de Mestrado em Geofísica. Universidade Federal do Pará. 2010. 90 p.

CASTRO, D. L.; CASTELO BRANCO, R. M. G. 4-D ground penetrating radar monitoring of a hydrocarbon leakage site in Fortaleza (Brazil) during its remediation process: a case history. Journal of Applied Geophysics, v. 54, p. 127144, 2003.

CORSEUIL, H. X.; ALVAREZ, P. J. J. Natural bioremediation perspective for BTX contaminated groundwater in Brazil: Effect on Ethanol. Wat. Sci. Tech., v. 34 (7-8), p. 311-318. 1996.

COUTINHO, R. C. P.; GOMES, C. C. Técnicas para remediação de aqüíferos contaminados por vazamentos de derivados de petróleo em postos de combustíveis. XVII Simpósio Brasileiro de Recursos Hídricos. 2007. 20 p.

DAVIS, J. L.; ANNAN, A. P. Ground-penetrating radar for high-resolution mapping of soil and rock stratigraphy. Geophysical Prospecting, v. 37, p. 531-551. 1989.

FEITOSA, F. A. C.; MANOEL FILHO, J. Hidrogeologia: Conceitos e Aplicações. Fortaleza: CPRM, LABHID, 1997. 389 p.

GSSI - GEOPHYSICAL SURVEY SYSTEMS, INC. Manual do TerraSIRch SIR System3000., 2003. $71 \mathrm{p}$.

HAYNIE, K. L.; KHAN, S. D. Shallow subsurface detection of buried weathered hydrocarbons using GPR and EMI. Marine and

Petroleum Geology, v. 77. 116 - 123 p. 2016.

MARQUES, S. G. Metodologia geofísica para contaminação por hidrocarbonetos - estudo de caso em posto de combustíveis. Dissertação de Mestrado em Geociências. Universidade de São Paulo. 2007. 113 p.

MENDES, R. L. R. Geofísica aplicada ao mapeamento de aquíferos da região metropolitana de Belém. Dissertação de Mestrado em Geofísica. Universidade Federal do Pará. 2000. 86 p. 
NASCIMENTO, M. H. D. Identificação de ambientes de sedimentação na área metropolitana de Belém a partir de perfis de poço. Dissertação de Mestrado em Geofísica. Universidade Federal do Pará. 2003. 48 p.

ORLANDO, L. Detection and analysis of LNAPL using the instantaneos amplitude and frequency of ground-penetrating radar data. Geophysical Prospecting, v. 50, p. 27-41. 2002.

PEDROSA, T. R. M. A. M. Caracterização de plumas contaminantes de hidrocarbonetos em postos de abastecimento em Fortaleza, usando o Método Eletromagnético Radar de Penetração do Solo (GPR). Dissertação de Mestrado em Geologia. Universidade Federal do Ceará. 2004. 135p.

PETTERSSON, K. J.; NOBES, D. C. Environmental geophysics at Scott Base: ground penetrating radar and electromagnetic induction as tools for mapping contaminated ground at Antarctic research bases. Cold Regions Science and Technology, v. 37, p.187-195. 2003.

SAUCK, W.A.; ATEKWANA, E.A.; NASH, M.S. High Conductivities Associated with an LNAPL Plume Imaged by Integrated Geophysical Techniques. Journal of Environmental and Engineering Geophysics, v. 2, p. 203-212. 1998.

SILVA, M. A. S. Investigação geofísica da contaminação por derivados de hidrocarbonetos nas redondezas do Posto Cristal (Belém-PA). Dissertação de Mestrado em Geofísica. Universidade Federal do Pará. 2013.90 p. 